\title{
Antidepressant-induced mania or hypomania in DSM-5
}

\author{
Takeshi Terao• Teruaki Tanaka
}

Received: 7 October 2013 / Accepted: 24 October 2013 / Published online: 19 November 2013

(C) Springer-Verlag Berlin Heidelberg 2013

To the Editor:

In contrast to DSM-IV-TR, DSM-5 adds the note to the diagnostic criteria of manic episodes as follows: "A full manic episode that emerges during antidepressant treatment but persists at a fully syndromal level beyond the physiological effect of that treatment is sufficient evidence for a manic episode and, therefore, a bipolar I diagnosis" (American Psychiatric Association 2013). Also, hypomanic episodes have a similar note in DSM-5 (American Psychiatric Association 2013). These notes seem to widen the concept of bipolar disorder because patients developing mania or hypomania during antidepressant treatment beyond the physiological effect can be diagnosed as bipolar I or II in DSM-5 although they were diagnosed as suffering from substance-induced mood disorder in DSM-IV-TR.

Back to DSM-III-R, manic episodes should have been diagnosed in cases that are apparently precipitated by antidepressants because DSM-III-R had a note that "somatic antidepressant treatment that apparently precipitates a mood disturbance should not be considered an etiologic organic factor" in the diagnostic criteria of manic episode (Goodwin and Jamison 2007). According to Dunner (a member of the DSM-IV task force), "There was a sense from the Task Force that bipolar conditions should not be over-diagnosed in the community. Therefore, hypomanic episodes occurring in response to treatment with antidepressant pharmacotherapy would not count toward the diagnosis of bipolar II. However, it is difficult to induce mania or hypomania in a true unipolar depression: "there is likelihood that patients who develop mania or hypomania in response to treatment are actually

\section{T. Terao $(\bowtie)$}

Department of Neuropsychiatry, Faculty of Medicine, Oita

University, Idaigaoka 1-1, Hasamamachi, Yufu, Oita 879-5593,

Japan

e-mail: terao@med.oita-u.ac.jp

T. Tanaka

Department of Psychiatry, Hokkaido University Graduate School of Medicine, Sapporo, Japan bipolar." (American Psychiatric Association 1987). Thereafter, Chun and Dunner (2004) suggest that the rate of antidepressant-induced hypomania in major depressive disorder is very low and that antidepressant treatment cannot make a unipolar patient bipolar.

Recently, Dumlu et al. (2011) confirmed that unipolar depression with a history of treatment-induced mania, bipolar I, and bipolar II clustered together in contrast to unipolar depression without manic switch. In this point, DSM-5 seems to be appropriately coming back to DSMIII-R. Nonetheless, beyond the physiological effect in the notes of DSM-5 should be deleted because patients who develop mania or hypomania in response to treatment may be actually bipolar (American Psychiatric Association 1987; Chun and Dunner 2004), and it seems difficult to determine whether manic or hypomanic state persists beyond the physiological effect in individual patients, inducing low reliability.

\section{Conflict of interest None.}

\section{References}

American Psychiatric Association (1987) Diagnostic and statistical manual of mental disorders, 3rd edn, revised (DSM-III-R). American Psychiatric Publishing, Washington, DC, USA, pp 216-217

American Psychiatric Association (2013) Diagnostic and statistical manual of mental disorders, 5th edition (DSM-5). American Psychiatric Publishing, Washington, DC, USA, pp 124-125

Chun BJDH, Dunner DL (2004) A review of antidepressant-induced hypomania in major depression: suggestions for DSM-V. Bipolar Disord 6:32-42

Dumlu K, Orhon Z, Özerdem A, Tural Ü, Ulas H, Tunca Z (2011) Treatment-induced manic switch in the course of unipolar depression can predict bipolarity: cluster analysis based evidence. J Affect Disord 134:91-101

Goodwin FK, Jamison KR (2007) Manic-depressive illness: bipolar disorders and recurrent depression, 2nd edition, Oxford University Press, New York, USA, pp 93 